\title{
Mental Health Problems among Clinical Psychologists: Stigma and its Impact on Disclosure and Help-seeking
}

\section{Journal of Clinical Psychology (in press)}

Authors' Information:

Dr Stacie Tay (corresponding author), Dr Kat Alcock \& Dr Katrina Scior Clinical Psychologist, Senior Clinical Tutor, Senior Lecturer

Clinical Educational \& Health Psychology, University College London, Gower Street,

London WC1E 6HB

Stacie.tay.13@ucl.ac.uk, k.alcock@ucl.ac.uk, k.scior@ucl.ac.uk

Corresponding author:Stacie Tay, stacie.tay.13@ucl.ac.uk

Running title: Mental Health Problems among Clinical Psychologists

Keywords: stigma; disclosure; help-seeking; mental health problems; clinical psychologists 


\begin{abstract}
Objective(s): To assess the prevalence of personal experiences of mental health problems among clinical psychologists, external, perceived and self-stigma among them, and stigma-related concerns relating to disclosure and help-seeking.

Method: Responses were collected from 678 UK-based clinical psychologists through an anonymous web survey consisting of the Social Distance Scale, Stig-9, Military Stigma Scale, Attitudes towards Seeking Professional Psychological Help Scale-Short Form, Secrecy Scale, alongside personal experience and sociodemographic questions.

Results: Two-thirds of participants had experienced mental health problems themselves. Perceived mental health stigma was higher than external and self-stigma. Participants were more likely to have disclosed in their social than work circles. Concerns about negative consequences for self and career, and shame prevented some from disclosing and help-seeking.

Conclusions: Personal experiences of mental health problems among clinical psychologists may be fairly common. Stigma, concerns about negative consequences of disclosure and shame as barriers to disclosure and help-seeking merit further consideration.
\end{abstract}

Keywords: stigma; disclosure; help-seeking; mental health problems; clinical psychologists 


\section{Introduction}

According to latest UK figures, $41 \%$ of adults report having experienced a diagnosable mental health problem at some point in their life, and around $27.7 \%$ have received diagnoses by professionals (Mental Health Foundation, 2016). Mental health problems may be even more common among mental health professionals because work in this area places high emotional demands and stresses on practitioners, and to start off with, those with lived experience may be more likely to be attracted to work in this field (American Psychological Association [APA], 2010; Smith \& Moss, 2009). However, as opposed to the extensive research conducted with the general public, we know relatively little about the mental health of providers of mental health services. The culture within health and mental health professions may leave their members viewing mental health problems as a weakness, and feeling that they should be mentally resilient and able to cope on their own. Correspondingly, they may experience shame and embarrassment and fear being judged negatively by the public, their family, friends, employers and co-workers when they do develop mental health problems (Corrigan, 2004; Garcia \& Crocker, 2008; Garelick, 2012; Kessler et al., 2001; Sirey et al., 2001). Due to concerns about confidentiality, fears that their career prospects would be adversely affected and negative experiences of past help, they are often reluctant to disclose their difficulties and seek help (Garelick, 2012; Hassan, Ahmed, White \& Galbraith, 2009).

Clinical psychologists in the US found the idea of seeking help psychologically threatening, 'self-indulgent' and stigmatising (Walsh \& Cormack, 1994). They feared adopting the role of the client and being viewed as professionally incompetent by employers, colleagues and faculty members (Dearing, Maddux, \& Tangney, 2005; Walsh \& Cormack, 1994). Similarly, perceived stigma (i.e. the belief that others hold negative stereotypes about people who experience mental health problems) from faculty members and the public predicted the 
attitudes of English trainee clinical psychologists towards seeking therapy (Digiuni, Jones, \& Camic, 2013).

Other factors found to affect disclosure and help-seeking include the type of mental health problem and disclosure target. Adults in the Dutch and American general population (Bos, Kanner, Muris, Janssen, \& Mayer, 2009; Pandya, Bresee, Duckworth, Gay, \& Fitzpatrick, 2011), British doctors (Hassan et al., 2009), and British clinical psychologists (Aina, 2015) were more comfortable disclosing mental distress to family and friends than to colleagues or employers. Furthermore, higher levels of stigma are associated with mental health problems that are more visible, or perceived as more dangerous, disruptive or less 'curable' (Avery et al., 2013; Gilchrist et al., 2011). As such, schizophrenia, bipolar disorder, alcoholism and drug addictions are more heavily stigmatised than anxiety, depression and eating disorders (Angermeyer \& Matschinger, 2003; Griffiths et al., 2006; Marie \& Miles, 2008).

Evidence on the mental health of mental health professionals, and clinical psychologists specifically, is limited and mostly either dated or derived from small-scale studies. What is known should give rise to concern about the limited attention paid to this issue. Psychologists in the US have been suggested to experience high levels of personal distress (Guy, Poelstra \& Stark, 1989), depression (Pope \& Tabachnick, 1994), and higher rates of suicide and suicidal ideation than the public (APA, 2010). This has been attributed to occupational vulnerabilities, including repeated exposure to distressing and emotionally intense material, worries about client safety, pressure to meet targets, professional isolation, and poor work-life balance (APA, 2010; Smith \& Moss, 2009). Almost half of the psychologists surveyed had not disclosed or sought help in response to suicidal thoughts (APA, 2010). In the UK, in a study of 101 clinical psychologists, 29.4\% met caseness on the General Health Questionnaire (GHQ-28) (Cushway \& Tyler, 1994). 
Professional guidance notes that downplaying or ignoring signs of mental health problems and circumventing appropriate help-seeking may exacerbate existing or lead to new mental health problems, and impair clinicians' functioning, fitness to practice and ability to provide quality care (APA, 2000, 2010; Health and Care Professions Council, 2015). In a study by Pope, Tabachnick, and Keith-Spiegel (1987), 59.6\% of American psychologists reported having worked despite being too distressed to be helpful, while $36.7 \%$ indicated that the quality of care they provided was affected by their distress. It is therefore critical that clinicians acknowledge difficulties and take timely action to manage their stress and mental health. Furthermore, codes of professional behaviour designed to safeguard the public expect psychologists to maintain standards of proficiency and fitness to practice (e.g. Health and Care Professions Council, 2015). However, the role of clinical psychologists as helpers and a discourse of 'us and them' when referring to clinicians and service users may leave them feeling apprehensive about 'crossing over' and adopting the role of client.

This study set out to assess the extent to which clinical psychologists in the UK report lived experience (i.e. personal experience of one or more self-defined mental health problems, including depression, anxiety disorders, bipolar disorder, psychosis, addictions and eating disorders), their views on disclosure and help-seeking, and to what extent stigma is a concern when they are faced with considering disclosure or seeking help in relation to mental health problems they experience themselves. We hypothesised that disclosure would be influenced by disclosure target and type of mental health problem experienced. In particular, we predicted that clinical psychologists, like the general population, would be more willing to disclose their mental health problems to people within their social circles (family and friends) than to work colleagues and employers, and less willing to disclose heavily stigmatised mental health problems (bipolar disorder, psychosis and addiction) than less stigmatised ones (depression, anxiety and eating disorders). 
We further hypothesised that clinical psychologists would perceive others as holding more negative attitudes towards people with mental health problems than they themselves (perceived versus external stigma, Barney et al., 2006; Link \& Phelan, 2001), and that they would be less likely to internalise and adopt negative societal attitudes (self-stigma, Corrigan \& Watson, 2002). Lastly, we predicted that perceived and self-stigma and fears about the negative consequences of disclosure and help-seeking (being judged negatively, negative impact on career and self-image, and shame) would be positively associated with reluctance to disclose, at least within a work setting, and seek help.

\section{Method}

\section{Participants}

Participants were recruited via the mailing list of the British Psychological Society's Division of Clinical Psychology (DCP), which at the time of this survey had around 3600 qualified clinical psychologists as subscribers. A total of 892 individuals responded to an email inviting list members to participate in the study. Sixty-four respondents were screened out at an early stage as they were still in training and a further 150 respondents accessed but did not complete the survey. The final sample comprised 678 qualified clinical psychologists resident in the UK, around $19 \%$ of those on the DCP email list who met the study's inclusion criteria. Of these $82.2 \%$ were female, $91.6 \%$ were white, and the majority $(84.2 \%)$ were in their 30 s to 50s, similar to the general make-up of the profession in the UK (Longwill, 2015). They showed a wide range of professional experience, with $26.4 \%$ qualified as clinical psychologists over 20 years ago, $27.9 \%$ qualified 11 to 20 years, $36.1 \%$ qualified two to ten years, and $9.4 \%$ less than two years.

A power analysis was informed by Hassan et al.'s (2009) study, in which fear of stigma and negative career implications emerged as the main predictors of doctors' willingness to disclose or conversely conceal their mental health problems $(r=.19)$. This indicated a required 
sample size of $\mathrm{N}=68$ for multiple regression analyses with four predictor variables, using G*Power 3.1 (Faul, Erdfelder, Lang, \& Buchner, 2007) with alpha set at 5\% and power at $80 \%$.

\section{Procedure}

Data were collected via an electronic survey using the Qualtrics software. The survey was piloted with eight qualified clinical psychologists from the authors' work places, and revised in line with their feedback. Thereafter clinical psychologists were invited by email to participate in the study via the DCP's mailing list. This list has around 3,600 members, not all of whom have completed their professional qualification. The email invitation provided details of the study and an electronic link to the survey. Invitations were sent in June 2015, with three follow-ups over four months. The study was also advertised in Clinical Psychology Forum, the DCP publication sent to all DCP members. No incentives were offered. The study received ethical approval from the authors' institutional research ethics committee.

\section{Measures}

The survey included demographic questions (e.g. gender, ethnicity, age bracket, number of years since qualifying, type of mental health problem(s) experienced and questions on disclosure and help-seeking), and questions exploring external, perceived and self-stigma as well as attitudes towards disclosure and help seeking, taken from five published scales, see below. Questions on stigma were posed to all respondents regardless of whether they reported having experienced mental health problems. Questions regarding participants' personal experiences of mental health problems, disclosure and help-seeking relating to current and past mental health problems were also included in the survey. Unless stated differently below, all questions were rated on a four-point Likert scale (1=strongly disagree to 4=strongly agree).

\section{External Stigma}

The Social Distance Scale (SDS) (Link, Cullen, Frank, \& Wozniak, 1987) was used to assess participants' external stigma and had very good internal consistency $(\alpha=.92)$ (Link et 
al., 1987). It was adapted to increase its relevance and applicability to this study's population by omitting the original vignette and two of the original seven items (i.e., "How would you feel about renting a room in your home to someone like Jim Johnson" and "How would you feel about having someone like Jim Johnson as the caretaker of your children?"), and rewording items, e.g. "How would you feel about introducing Jim Johnson to a young woman you are friendly with?" was replaced with "I would not spend the evening socialising with someone who has a mental health problem". Possible scores range from 5 to 20 with higher scores indicating greater desire to distance oneself from persons with mental health problems.

\section{Perceived Stigma}

The 9-item Stig-9 (Gierk, Murray, Kohlmann, \& Löwe, 2013) was used to assess participants' perceived stigma. It asks questions such as, "I think that most people consider mental health problems to be a sign of personal weakness". The authors stated that it had good internal consistency but this could not be verified, as the article that described its psychometric evaluation was under review for publication. Possible scores range from 9 to 36, with higher scores indicating higher perceived mental health stigma.

\section{Self-Stigma}

The 10-item self-stigma subscale of the Military Stigma Scale (MSS) was used to measure self-stigma. It had good internal consistency $(\alpha=.87)$ (Skopp et al., 2012) and asks questions such as, "It would make me feel inferior to ask a therapist for help.". Possible scores range from 10 to 40, with higher scores reflecting greater self-stigma. As the MSS was standardised on military personnel, it was piloted and its reliability examined to ensure its transferability to clinical psychologists.

\section{Concealment}

The 9-item Secrecy Scale was used to assess participants' attitudes towards disclosure/concealment of mental health problems. It had good internal consistency $(\alpha=.84)$ 
(Link, Struening, Neese-todd, Asmussen, \& Phelan, 2002) and asks questions such as, "If I have ever been treated for a severe mental health problem, the best thing to do is to keep it a secret.". Possible scores range from 9 to 36, with higher scores indicating a greater desire to conceal current or past difficulties.

Help-seeking

The 10-item Attitudes towards Seeking Professional Psychological Help Scale-Short Form (ATSPPH-SF) (Fischer \& Farina, 1995) was used to assess participants' attitudes towards seeking professional psychological help. It had good internal consistency ( $\alpha=.77$ to .78) (Elhai, Schweinle, \& Anderson, 2008) and asks questions such as, "I might want to have psychological therapy in the future.". Possible scores range from 10 to 40, with higher scores indicating more positive attitudes towards seeking professional help.

\section{Statistical Analysis}

Data were analysed using SPSS version 22. Analyses of the psychometric properties of the scales with the present sample indicated that the Stig-9 $(\alpha=.89), \operatorname{MSS}(\alpha=.88)$ and Secrecy Scale $(\alpha=.80)$ had good internal consistency, while the SDS and ATSPPH-SF had acceptable internal consistency ( $\alpha=.72$ and $\alpha=.69$ respectively). Chi-square tests were used to analyse the effect that type of mental health problem and disclosure target had on willingness to disclose and seek help. One-way ANOVAs and independent samples t-tests were computed to assess differences in the different aspects of stigma, and attitudes to concealment and helpseeking on disclosure and help-seeking.

\section{Results}

\section{Lived Experience among Clinical Psychologists}

Of the 678 participants, $62.7 \%(n=425)$ reported having experienced a mental health problem(s) at some point in their lives. Almost half $(n=195)$ of these had experienced two or more different mental health problems, with $12.2 \%$ having experienced three or more. 
Depression and anxiety were the most common problems experienced. Of note, a small number had experienced bipolar disorder, psychosis and addiction, see Table 1.

- Insert Table 1 about here -

\section{Stigma among Clinical Psychologists}

High levels of stigma were defined as an average score above the midpoint of the scale's possible range of scores (Ritsher \& Phelan, 2004). Participants' mean total score for external stigma (scale mid-point 12.5$)$ was $6.96(S D=2.12)$, with scores ranging from 5 to 17 . For perceived stigma (scale mid-point 22.5), their scores ranged from 9 to 35 with a mean score of $22.7(S D=4.9)$. Lastly, for self-stigma (scale mid-point 25), their scores ranged from 10 to 36, with a mean score of $18.4(S D=5.64)$. These scores support our hypotheses that clinical psychologists would show higher levels of perceived stigma than external and self-stigma.

\section{Disclosure of Mental Health Problems}

Participants' mean total score on the Secrecy Scale (scale mid-point 22.5) was 20.33 $(S D=4.23)$, with scores ranging from 10 to 36 . This indicates that they did not typically perceive a high need to conceal mental health problems from others. Looking at data pertaining to the 425 participants who reported lived experience of mental health problems, 46 participants (10.8\% of this sub-sample) had not disclosed their difficulties to anyone. Of these, $58.7 \%(n=27)$ had experienced one mental health problem, while the rest had experienced two to five mental health problems (suggesting that non-disclosure is not simply the result of difficulties being minor or temporary). Those who had disclosed were more likely to have done so in their social circles than in their work settings, $\chi^{2}(1)=26.22, p<.001$. In line with hypothesis 2, more participants had disclosed to their family (68.2\%) and/or friends $(65.2 \%)$, compared to $44.5 \%$ who had disclosed within a work setting, including $37.9 \%$ who had disclosed to colleagues or peers, and $25.6 \%$ to employers.

The perceived quality of disclosure experiences was measured on a scale of 0 (very 
negative) to 10 (very positive). Participants reported the most positive experience of disclosing to friends $(M=7.49, S D=1.93)$, followed by family $(M=6.74, S D=2.53)$ and colleagues/peers $(M=6.65, S D=2.55)$. Their most negative experiences related to disclosure to employers $(M$ $=4.95, S D=3.21$.

Looking at the level of stigma associated with different types of mental health problems, against our predictions, no difference was observed between disclosure rates for heavily and less stigmatised mental health problems. Of those who had experienced heavily stigmatised mental health problems (psychosis and addiction), $11.8 \%(n=4)$ had disclosed these to no one, compared to $11.1 \%(n=40)$ who had not disclosed less stigmatised mental health problems (depression, anxiety and eating disorders), $\chi^{2}(1)=p=.781$.

\section{Help-seeking for Mental Health Problems}

Participants' mean total score on the ATSPPH-SF (scale mid-point 25) was 20.33 (SD $=4.23$ ), with scores ranging from 10 to 36 . This indicates that participants typically did not hold overly positive attitudes towards seeking professional help. Of the 425 participants who had experienced a mental health problem(s), 84\% $(n=357)$ had sought help. Of these, more than half had sought help from their General Practitioner (53.2\%), and a minority from a private psychiatrist (3.8\%), see Table 2. - Insert Table 2 below -

Participants rated the quality of the help received on a scale from 0 (very negative) to 10 (very positive). They reported the most positive experiences of seeking help from private psychotherapists $(M=7.86, S D=2.06)$, followed by private clinical psychologists $(M=7.61$, $S D=2.57)$, NHS clinical psychologists $(M=6.44, S D=3.23)$, GPs $(M=6.35, S D=2.72)$, NHS psychotherapists $(M=5.8, S D=3.15)$ and NHS psychiatrists $(M=5.29, S D=2.66)$. Their most negative experiences of seeking help related to private psychiatrists $(M=4.38, S D$ $=3.72)$. 
Looking at the impact of stigma on help-seeking, against predictions, rates of helpseeking were similar for both groups, with $83.9 \%(n=303)$ of those reporting less stigmatised problems (depression, anxiety and eating disorders) and $88.2 \%(\mathrm{n}=30)$ of those reported heavily stigmatised problems (psychosis and addiction) having sought help, $\chi^{2}(1)=.435, p=$ $.510,11.8 \%$. Of note, $14.6 \%(\mathrm{n}=62)$ had not sought help from anyone.

\section{Stigma, Fear of Consequences, Disclosure within Work Contexts and Help-Seeking}

Finally, we assessed support for our prediction that stigma and fear of the consequences of disclosure (being judged negatively, impact on career, impact on self-image), and shame would be associated with reluctance to disclose and seek help. Of the 46 participants who had not disclosed their current or past mental health problems to anyone, over two thirds cited being judged negatively and fear about a negative impact on their career as factors that prevented them from disclosing. Shame and negative impact on self-image were also important considerations for them, see Table 3. - Insert Table 3 below -

When comparing those who had disclosed their difficulties in work, social settings, or to no one on the measures of perceived, self- and external stigma as well as concealment, significant differences emerged on the $\operatorname{MSS}(F(2,389)=11.747, p<.001)$ and the Secrecy scale $=(F(2,379)=7.099, p=.001)$. Post-hoc tests with Bonferroni correction showed that those who had disclosed to no one showed higher levels of self-stigma $(M=21.860, S D=$ 6.462) than those who had disclosed at work $(M=17.414, S D=5.571), d=0.737$, or in their social circle $(M=18.673, S D=5.829), d=0.518$. They also showed higher concealment $(M=$ 22.783, $S D=3.681$ ) than those who had disclosed current or past difficulties in a place of work $(M=20.217, S D=4.390), d=0.633$, but not compared to those who had disclosed in their social circle $(M=21.151, S D=4.397)$.

Turning to help-seeking, for the 68 participants who had not sought professional help for their difficulties the four feared negative consequences were of concern, but less so than in 
preventing disclosure, see Table 3. Post-hoc tests with Bonferroni correction showed that those who had not sought professional help showed higher levels of self-stigma $(M=21.661, S D=$ 5.669) than those who had sought professional help $(M=17.839, S D=5.765), t(411)=4.920$, $p<.001, d=0.669$. The former also expressed less positive attitudes to help-seeking $(M=$ 28.095, $S D=4.102)$ than those who had sought professional help $(M=31.243, S D=3.593), t$ $(407)=-6.252, p<.001, d=0.816$.

\section{Discussion}

This is the largest study to date of mental health problems, stigma and views on disclosure and help-seeking amongst clinical psychologists in the UK. Approximately twothirds of participants reported lived experience of mental health problems. This figure exceeds latest estimates of a $41 \%$ lifetime prevalence of diagnosable mental health problems among adults in the UK (Mental Health Foundation, 2016) - the difference may indicate high levels of lived experience in this population or conversely may be due to self-selection bias in the present study. The proportions reporting lived experience are very similar to those found in a recent survey of 348 clinical psychologists in training in the UK (Grice, Alcock, \& Scior, under review), but of course this does not rule out bias due to those who have personal experience of mental health problems being more likely to participate in a study of this nature. Future studies should seek to counter response biases while assessing the prevalence of lived experience among mental health professionals, for example by seeking anonymous data using personal response systems.

Findings of higher levels of perceived stigma compared to external and self-stigma found in this study suggest that, whilst clinical psychologists are mindful of the stigma attached to mental health problems, as a whole they were unlikely to stigmatise others or themselves, at least as measured on a standardised scale. However, the $11 \%$ of participants who had not disclosed personal mental health problems to anyone showed higher levels of self-stigma and 
cited fear of negative effects on their career, public and self-image and shame as factors that had stopped them from disclosing their difficulties, or from seeking help.

Previous research suggests that increased and accurate knowledge of, and contact with people with mental health problems is associated with higher perceived stigma and lower external and self-stigma (Corrigan, Morris, Michaels, Rafacz, \& Ruesch, 2012; Gilchrist et al, 2011). This may account for the low levels of external stigma found in the current study, which are in line with a recent Australian survey in which psychologists showed low levels of stigmatising attitudes (Reavley, Mackinnon, Morgan, \& Jorm, 2014). However, Servais and Saunders (2007) found clinical psychologists in the US to hold relatively negative attitudes towards people with psychosis and diagnoses of personality disorders. As perceived stigma was not assessed in relation to different types of mental health problems in the present study, we are not able to conclude whether the present participants were simply less stigmatising than those in some other studies, or whether their attitudes might have emerged as more negative if they had been asked about more heavily stigmatised problems.

As hypothesised, participants with lived experience were more likely to have disclosed to people in their social circles rather than those in their work settings, and reported more positive experiences of disclosure to the former. These findings are consistent with findings from a previous qualitative study of British clinical psychologists (Aina, 2015), and with the disclosure preferences of both British doctors and people in the Dutch, American and British general population (Bos et al., 2009; Hassan et al., 2009; Pandya et al., 2011; Time to Change, 2015). Of note though, $44.5 \%$ in our study had disclosed to colleagues and/or employers.

\section{Stigma, Disclosure and Help-seeking}

In line with previous research (Corrigan, 2004; Sartorius, 2007; Schomerus \& Angermeyer, 2008), self-stigma was associated with reluctance to disclose and seek help. Some studies have concluded that, in the general population, individuals are less likely to disclose 
more heavily stigmatised mental health problems (psychosis, bipolar disorder, addiction) compared to less stigmatised ones (depression, anxiety, eating disorders), owing to higher levels of anticipated discrimination (Rüsch, Brohan, Gabbidon, Thornicroft, \& Clement, 2014). In contrast, a review on workplace disclosure concluded that lower levels of disability resulting from the respective mental health problem together with higher concealability are negatively associated with workplace disclosure (Brohan et al., 2012). Our findings of disclosure rates that did not vary between more or less stigmatised mental health problems are more in line with Brohan et al. (2012).

Similarly, and in contrast to evidence of lower help-seeking for more heavily stigmatised mental health problems (Schomerus \& Angermeyer, 2008), rates of help-seeking did not vary between more and less stigmatised problems in the current study. Whether these findings are due to clinical psychologists' good understanding of mental health problems and of the evidence in favour of treatment, both of which might facilitate early self-identification and help-seeking where indicated, concern for the potential impact of difficulties on one's capacity to function in the social and work sphere, duty of care for service users, or indeed concealability are questions for further research.

\section{Fear of Consequences, Shame, Disclosure and Help-seeking}

Self-stigma, fear of a negative impact on (self-) image and shame negatively influenced disclosure and help-seeking. These findings are consistent with evidence that people with mental health problems may avoid disclosure and treatment seeking/participation in order to avoid experiencing shame and embarrassment, and being judged negatively (Corrigan, 2004; Sirey et al., 2001). However, research also suggests that concealing a stigmatised condition may exacerbate feelings of shame, stress and isolation (Pachankis, 2007; Rüsch et al., 2009, 2009b).

\section{Strengths and Limitations}


While the large sample size is a strength of this study, self-selection and non-response biases may have skewed the results and limited the representativeness and generalizability of this study's findings. We attempted to counter such bias by sending three separate invitations to all those on the DCP mailing list but this is clearly a potential limitation.

The fact that $81.9 \%$ of qualified participants who accessed the survey completed it, suggests that participants viewed this as important research. This was also evident in some of the communications participants sent separately to the research team, including comments such as, "I think this is a hugely important area of research", and "...stigma...is something as a profession I think we are very bad at acknowledging: The possibility that we... are as vulnerable as the clients we work with....and possibly the mask of the profession is more difficult to remove when we need help... There is an implicit message that we must be more 'normal' than everyone else, and a history of mental health problems (are) a sign of weakness to be kept out of the profession".

Furthermore, we acknowledge that the very endeavour of basing research into mental health stigma on diagnostic labels and of categorising difficulties as heavily and less stigmatised, while in line with much research in the stigma field, may be seen as problematic. Above all, it ignores individual experience which is undoubtedly influenced by a wide range of factors beyond diagnostic labels, and where clinical psychologists are concerned, their more nuanced understanding of mental health problems and comorbidities.

\section{Conclusions}

Personal experience of mental health problems was common among the clinical psychologists sampled and more than half were reluctant to disclose these to colleagues and superiors. While in many instances there may be little need for disclosure, self-stigma and a perceived need for concealment, as well as fears of being judged negatively and a negative impact on self-image, and shame prevented some from disclosing and seeking help. On a 
positive note, $89 \%$ of those personally affected had disclosed their difficulties to someone, including $44.5 \%$ who disclosed in their work setting, and $84 \%$ who sought professional help.

In the context of an increasingly target and outcome-driven health services culture in the UK, support for mental health professionals who experience mental health problems themselves merits consideration at both the individual and organisational level, as does how to promote openness about personal struggles. Furthermore, even at training level, there is an emphasis on emotional resilience and an unspoken belief that disclosing one's mental health problems may be viewed with mistrust and could result in discrimination. Therefore within clinical psychology and across mental health professions more generally, unspoken beliefs that 'experts' should be immune to human distress need to be challenged more openly. Furthermore, a change in the health service culture more generally is needed to encourage open conversations about lived experience in the workplace with the aim of reducing stigma and shame associated with these. Ultimately interventions that support the wellbeing of mental health professionals are likely to positively affect the quality of care received by other users of mental health services. The effectiveness of such interventions in increasing the willingness of mental health professionals to disclose and seek help, as well as the knock-on effect on their ability to provide quality care to clients, should be carefully evaluated. Moreover, as most studies conducted to date have had a negative focus, it would be beneficial to explore the positive aspects of lived experience of mental health problems. This could further serve to destigmatise mental health problems. 


\section{References}

Aina, O. (2015). Clinical psychologists' personal experiences of psychological distress (Unpublished doctoral dissertation). University of East London, London.

American Psychological Association. (2000). Professional health and well-being for $\begin{array}{lllll}\text { psychologists. } & \text { Retrieved } & \text { July } & 28, & \text { 2004, }\end{array}$ http://www.psychpage.com/ethics/wellness.pdf

American Psychological Association (2010). Survey findings emphasize the importance of self-care for psychologists. Retrieved October 5, 2010 from http://www.apapracticecentral.org/update/2010/08-31/survey.aspx.

Angermeyer, M. C., \& Matschinger, H. (2003). Public beliefs about schizophrenia and depression: Similarities and differences. Social Psychiatry and Psychiatric Epidemiology, 38(9), 526-34.

Avery, J., Dixon, L., Adler, D., Oslin, D., Hackman, A., First, M., ... Siris, S. (2013). Psychiatrists' attitudes toward individuals with substance use disorders and serious mental illness. Journal of Dual Diagnosis, 9(4), 322-326.

Barney, L. J., Griffiths, K. M., Jorm, A. F., \& Christensen, H. (2006). Stigma about Depression and its Impact on Help-seeking Intentions. The Australian and New Zealand Journal of Psychiatry, 40(1), 51-4. doi:10.1111/j.1440-1614.2006.01741.x

Bos, A., Kanner, D., Muris, P., Janssen, B., \& Mayer, B. (2009). Mental illness stigma and disclosure: Consequences of coming out of the closet. Issues in Mental Health Nursing, 30(8), 509-513.

Brohan, E., Henderson, C., Wheat, K., Malcolm, E., Clement, S., Barley, E.A., .... Thornicroft, G. (2012). Systematic review of beliefs, behaviours and influencing factors associated with disclosure of a mental health problem in the workplace. BMC Psychiatry, 12:11. 
Corrigan, P. (2004). How stigma interferes with mental health care. American Psychologist, $59(7), 614-625$.

Corrigan, P.W., Morris, S.B., Michaels, P.J., Rafacz, J.D., \& Ruesch, N. (2012). Challenging the public stigma of mental illness: A meta-analysis of outcome studies. Psychiatric Services, 63, 963-973.

Corrigan, P. W., \& Watson, A. C. (2002). The Paradox of Self-Stigma and Mental Illness. Clinical Psychology: Science and Practice, 9(1), 35-53. doi:10.1093/clipsy.9.1.35

Cushway, D., \& Tyler, P. A. (1994). Stress and coping in clinical psychologists. Stress Medicine, 10, $35-42$.

Dearing, R. L., Maddux, J. E., \& Tangney, J. P. (2005). Predictors of psychological help seeking in clinical and counseling psychology graduate students. Professional Psychology: Research and Practice, 36(3), 323-329.

Digiuni, M., Jones, F. W., \& Camic, P. M. (2013). Perceived Social stigma and attitudes towards seeking therapy in training: A cross-national study. Psychotherapy (Chicago, Ill.), 50(2), 213-23.

Elhai, J. D., Schweinle, W., \& Anderson, S.M. (2008). Reliability and Validity of the Attitudes Toward Seeking Professional Psychological Help Scale-Short Form. Psychiatry Research, 159, 320-329.

Faul, F., Erdfelder, E., Lang, A.-G., \& Buchner, A. (2007). G*Power 3: a flexible statistical power analysis program for the social, behavioral, and biomedical sciences. Behavior Research Methods, 39(2), 175-91.

Fischer, E. H., \& Farina, A. (1995). Attitudes toward seeking professional psychological help: A shortened form and considerations for research. Journal of College Student Development, 36, 368-373. 
Garcia, J. A., \& Crocker, J. (2008). Coping with the stigma of depression: Egosystem and ecosystem goals. Social Science and Medicine, 67, 453-462.

Garelick, A. I. (2012). Doctors' health: Stigma and the professional discomfort in seeking help. The Psychiatrist, 36(3), 81-84.

Gierk, B., Murray, A. M., Kohlmann, S., \& Löwe, B. (2013). Measuring the Perceived Stigma of Mental Illness with Stig-9: A Re-conceptualisation of the PerceivedDevaluation-Discrimination-Scale. Available: https://commons.wikimedia.org/w iki/File:Stig9.pdf (June 14, 2016).

Gilchrist, G., Moskalewicz, J., Slezakova, S., Okruhlica, L., Torrens, M., Vajd, R., \& Baldacchino, A. (2011). Staff regard towards working with substance users: A European multi-centre study. Addiction, 106(6), 1114-1125. Grice, Alcock, \& Scior (under review). Lived experience of mental health problems among clinical psychology trainees: disclosure and mental health stigma. Manuscript submitted for publication.

Grice, T., Alcock, K., \& Scior, K. (under review). Mental health disclosure among clinical psychologists in training: Perfectionism and pragmatism

Griffiths, K. M., Nakane, Y., Christensen, H., Yoshioka, K., Jorm, A. F., \& Nakane, H. (2006). Stigma in response to mental disorders: a comparison of Australia and Japan. BMC Psychiatry, 6, 21.

Guy, J. D., Poelstra, P. L., \& Stark, M. J. (1989). Personal distress and therapeutic effectiveness: National survey of psychologists practicing psychotherapy. Professional Psychology: Research and Practice, 20(1), 48-50.

Hassan, T. M., Ahmed, S. O., White, A. C., \& Galbraith, N. (2009). A postal survey of doctors' attitudes to becoming mentally ill. Clinical Medicine (London, England), 9(4), 327-32.

Health and Care Professions Council (2015). Standards of proficiency - practitioner psychologists. London: HCPC. 
Kessler, R. C., Berglund, P. A., Bruce, M. L., Koch, J. R., Laska, E. M., Leaf, P. J., ... Wang, P. S. (2001). The prevalence and correlates of untreated serious mental illness. Health Services Research, 36(6 Pt 1), 987-1007.

Link, B. G., Cullen, F. T., Frank, J., \& Wozniak, J. F. (1987). The social rejection of former mental patients: Understanding why labels matter. American Journal of Sociology, 92, 1461-1500.

Link, B. G., \& Phelan, J. C. (2001). Conceptualising stigma. Annual Review Sociology, 27, 363-385.

Link, B. G., Struening, E. L., Neese-todd, S., Asmussen, S., \& Phelan, J. C. (2002). On describing and seeking to change the experience of stigma. Psychiatric Rehabilitation Skills, 6(2), 201-231.

Longwill, A. (2015). Clinical psychology workforce project Division of Clinical Psychology UK. Leicester, UK: British Psychological Society.

Marie, D., \& Miles, B. (2008). Social distance and perceived dangerousness across four diagnostic categories of mental disorder. Australian and New Zealand Journal of Psychiatry, 42(2), 126-133.

Mental Health Foundation (2016). Fundamental Facts About Mental Health 2016. Mental Health Foundation: London. Retrieved June 14, 2017 from https://www.mentalhealth.org.uk/publications/fundamental-facts-about-mentalhealth-2016

Pachankis, J.E. (2007). The psychological implications of concealing a stigma: A cognitiveaffective-behavioral model. Psychological Bulletin, 133, 328-45.

Pandya, A., Bresee, C., Duckworth, K., Gay, K., \& Fitzpatrick, M. (2011). Perceived impact of the disclosure of a schizophrenia diagnosis. Community Mental Health Journal, 47(6), 613-621. 
Pope, K. S., Tabachnick, B. G., \& Keith-Spiegel, P. (1987). Ethics of practice. The beliefs and behaviors of psychologists as therapists. The American Psychologist, 42, 993-1006.

Pope, K.S. \& Tabachnick, B.G. (1994). Therapists as patients: A national survey of psychologists' experiences, problems, and beliefs. Professional Psychology: Research and Practice, 25(3), 247-258

Reavley, N.J., Mackinnon, A.J., Morgan, A.J. \& Jorm, A.F. (2014). Stigmatising attitudes towards people with mental disorders: A comparison of Australian health professionals with the general community. Australian and New Zealand Journal of Psychiatry, 48, $433-441$.

Ritsher, J. B., \& Phelan, J. C. (2004). Internalized stigma predicts erosion of morale among psychiatric outpatients. Psychiatry Research, 129, 257-265.

Rüsch, N., Brohan, E., Gabbidon, J., Thornicroft, G., \& Clement, S. (2014). Stigma and disclosing one's mental illness to family and friends. Social Psychiatry and Psychiatric Epidemiology, 49(7), 1157-1160.

Rüsch, N., Corrigan, P.W., Wassel, A., Michaels, P., Olschewski, M., Wilkniss, S, \& Batnia, K. (2009a). A stress-coping model of mental illness stigma: I. Predictors of cognitive stress appraisal. Schizophrenia Research, 110, 59-64.

Rüsch, N., Corrigan, P.W., Powell, K., Rajah, A., Olschewski, M., Wilkniss, S., \& Batia, K. (2009b). A stress-coping model of mental illness stigma: II. Emotional stress responses, coping behavior and outcome. Schizophrenia Research, 110, 65-71.

Sartorius, N. (2007). Stigma and mental health. Lancet, 370(9590), 810-1.

Schomerus, G., \& Angermeyer, M. C. (2008). Stigma and its impact on help-seeking for mental disorders: What do we know? Epidemiologia e Psichiatria Sociale, 17, 31-37.

Servais, L. M., \& Saunders, S. M. (2007). Clinical psychologists' perceptions of persons with mental illness. Professional Psychology: Research and Practice, 38(2), 214-219. 
Sirey, J. A, Bruce, M. L., Alexopoulos, G. S., Perlick, D. a, Friedman, S. J., \& Meyers, B. S. (2001). Stigma as a barrier to recovery: Perceived stigma and patient-rated severity of illness as predictors of antidepressant drug adherence. Psychiatric Services, 52(12), $1615-1620$.

Skopp, N. a, Bush, N. E., Vogel, D. L., Wade, N. G., Sirotin, A. P., McCann, R. a, \& Metzger-Abamukong, M. J. (2012). Development and Initial Testing of a Measure of Public and Self-stigma in the Military. Journal of Clinical Psychology, 68(9), 103647. doi:10.1002/jclp.21889

Smith, P. L., \& Moss, S. B. (2009). Psychologist impairment: What is it, how can it be prevented, and what can be done to address it? Clinical Psychology: Science and Practice, 16, 1-15.

Time to Change. (2015). Attitudes to Mental Illness 2014 Research Report. London: Time to Change. Retrieved June 14, 2017 from https://www.time-to-change.org.uk/researchreports-publications/campaign

Walsh, S. \& Cormack, M. (1994). "Do as we say but not as we do": Organisational, professional and personal barriers to the receipt of support at work. Clinical Psychology and Psychotherapy, 1(2): 101-110. 
Table 1

Clinical psychologists' experiences of mental health problems $(n=425)$

\begin{tabular}{lcc}
\hline Type of Mental Health Problem experienced & $n$ & $\%$ \\
\hline Mild to Moderate Depression & 297 & 69.9 \\
Anxiety & 179 & 42.1 \\
Other & 72 & 16.9 \\
Severe Depression & 55 & 12.9 \\
Eating Disorders & 47 & 11.1 \\
Addiction & 18 & 4.2 \\
Psychosis & 14 & 3.3 \\
Bipolar Disorder & 5 & 1.2
\end{tabular}

Note. Total \% exceeds $100 \%$ owing to comorbidities. 
Table 2

Help Sought for Current/ Past Mental Health Problems $(n=425)$

\begin{tabular}{lcc}
\hline Help sought from & $n$ & $\%$ \\
\hline General Practitioner & 226 & 53.2 \\
Private Psychotherapist & 194 & 45.6 \\
No one & 68 & 16 \\
Other & 66 & 13.5 \\
Private Clinical Psychologist & 56 & 12.2 \\
NHS Clinical Psychologist & 52 & 11.3 \\
NHS Psychotherapist & 48 & 10.1 \\
NHS Psychiatrist & 43 & 3.8 \\
Private Psychiatrist & 16 & \\
\hline
\end{tabular}

Note. $n$ and \% exceeded 425 and 100\% respectively owing to help-seeking from multiple health professionals. 
Table 3

Descriptive Statistics for Factors Preventing Disclosure and Help-Seeking

Disclosure

\begin{tabular}{cc}
$(n=46)$ & $(n=68)$ \\
\hline$n(\%)$ & $n(\%)$
\end{tabular}

Being judged negatively

$33(71.7)$

$24(35.3)$

Negative impact on career

Negative impact on self-image

Shame

Note. \% exceeded $100 \%$ as multiple responses were allowed.
$31(67.4)$ $25(36.8)$

$19(41.3)$

$22(32.4)$

$22(47.8)$

$23(33.8)$ 